\title{
Enhanced antitumor activity of combined megestrol acetate and arsenic trioxide treatment in liver cancer cells
}

\author{
YAN XIA ${ }^{1,2^{*}}$, XIANHAO LIU ${ }^{2 *}$, BEIBEI LIU ${ }^{2}$, XIAOSHI ZHANG ${ }^{1}$ and GENG TIAN ${ }^{2}$ \\ ${ }^{1}$ Department of Biotherapy Research Center, Sun Yat-sen University Cancer Center, \\ Guangzhou, Guangdong 510060; ${ }^{2}$ Department of Oncology, Shenzhen Second People's Hospital, \\ The First Affiliated Hospital of Shenzhen University, Shenzhen, Guangdong 518035, P.R. China
}

Received September 19, 2017; Accepted January 19, 2018

DOI: $10.3892 /$ etm.2018.5905

\begin{abstract}
Liver cancer is an aggressive malignancy with a very high fatality rate. Although megestrol acetate (MA) and arsenic trioxide (ATO) have shown an antitumor effect in liver cancer cells, the therapeutic benefits of MA or ATO alone in patients with liver cancer were limited. The aim of the present study was to elucidate whether the co-treatment of MA/ATO could enhance antitumor efficacy in liver cancer cell lines (Hep G2 and BEL 7402) and explore the underlying anti-cancer mechanisms. The cell viability, apoptotic response and expression levels of associated proteins were detected by Cell Counting Kit-8 assay, flow cytometry and western blotting, respectively. An xenograft model in nude mice bearing a Hep G2 tumor was used to estimate tumor growth in vivo. Co-treatment with MA/ATO markedly improved the inhibition of cell viability, enhanced apoptosis, and increased the phosphorylation of p38, c-Jun $\mathrm{N}$-terminal kinase $1 / 2$ and extracellular signal-regulated kinase $1 / 2$ on liver cancer cell lines. Furthermore, the tumor growth in the murine Hep G2 cancer xenograft model was significantly inhibited by combined treatment with MA/ATO. The results indicated that MA/ATO combined treatment enhanced antitumor efficacy and possessed potential application for treating liver cancer.
\end{abstract}

Correspondence to: Dr Xiaoshi Zhang, Department of Biotherapy Research Center, Sun Yat-sen University Cancer Center, 651 Dongfeng East Road, Guangzhou, Guangdong 510060, P.R. China

E-mail: zhangxsh@sysucc.org.cn

Dr Geng Tian, Department of Oncology, Shenzhen Second People's Hospital, The First Affiliated Hospital of Shenzhen University, 3002 Sungang West Road, Futian, Shenzhen, Guangdong 518035, P.R. China

E-mail: tiangeng_tg666@163.com

*Contributed equally

Key words: megestrol acetate, arsenic trioxide, liver cancer, antitumor, apoptosis

\section{Introduction}

Liver cancer, one of the most common primary malignancies with a high fatality rate, often responds poorly to current therapies (1). For instance, hepatocellular carcinoma (HCC) accounts for about $80-90 \%$ of primary liver cancers (2). Patients diagnosed with early stages of $\mathrm{HCC}$ were potentially cured by surgical resection, liver transplantation (TPX) or locoregional procedures such as radiofrequency ablation combined with chemoembolization (3). However, more than $50 \%$ of patients with HCC presented an advanced disease at diagnosis, while approximately two thirds of HCC patients had unresectable tumors with limited treatment options $(3,4)$. Various clinical trials reported that treatment of patients with unresectable HCC by single-agent chemotherapy had low response rates (0-20\%) with poor prognosis. However, combination chemotherapy had clinical efficacy with enhanced effectiveness when compare with single-agent treatment $(5,6)$. Therefore, combinations of chemotherapy drugs with two or more agents might facilitate the optimization for treating patients with liver cancers.

Normal human liver was modulated by sex hormones in morphology and function (7). Megestrol acetate (MA), a synthetic progestin with multiple drug actions, was widely used in management of endometrial carcinoma and breast carcinoma (8-11). Hepatoblastoma (HB) is a rare but the most common primary hepatic malignancy of infants and young children (12). Previous study showed that MA could inhibit the growth of HB-derived Hep G2 cells in vitro and in vivo (13). However, the underlying mechanism was not well understood. In addition, it was reported that variant liver estrogen receptors (ERs) were the strongest negative predictors of survival in inoperable HCC (14), which indicated the potential benefits of progestins on treatment of HCC.

Besides, arsenic trioxide (ATO), which have a remarkable therapeutic effect on treatment of APL (acute promyelocytic leukemia) (15), could induce apoptosis in solid tumor cell lines, such as cervical cancer cells, human sarcoma cells, hepatoblastoma cells and HCC cells (16-19). It was revealed that Mitogen Activated Protein Kinase (MAPK) pathway, including MAPK groups of ERK, JNK and p38, played an essential role in cellular responses, such as proliferation, differentiation, senescence and so on (20-22). Activation of 
MAPKs, such as p38 MAPK and JNK, were important for cancer prevention by drug therapy against cancer $(23,24)$. Previous study showed that ATO treatment activated both p38 MAPK and JNK pathway in Hela cells (18). In a similar vein, it was revealed that ATO could induce apoptosis with increase of cleaved-caspase- 3 and phosphorylation of $\mathrm{p} 38$ MAPK and JNK in two different sarcoma cell lines (HOS and HT1080 cell lines) (17). However, the result of a phase II clinical trial indicated that therapeutic effect of single-agent ATO was limited in treatment of HCC (25). Multiple studies further showed that some agents synergized with ATO in antitumor effect, such as $\mathrm{N}$-( $\beta$-elemene-13-yl) tryptophan methyl ester (ETME), sorafenib, icariin and genistein (26-29). Thus, combination treatment with ATO may be potential strategy with promising outcomes for patients with liver cancer.

In the present study, we investigated the antitumor activity and underlying mechanisms of MA/ATO combination in liver cancer cell lines (Hep G2 and BEL 7402 cells). It was showed that treatment of combined MA/ATO enhanced the inhibition of cell viability and apoptosis in liver cancer cells. In addition, the results provided evidences that MAPK signaling pathway was involved in the antitumor effect of MA/ATO combination.

\section{Materials and methods}

Cell lines and cell culture. Human liver cancer cell lines (Hep G2 and BEL 7402) were obtained from Shanghai Cell Bank (Shanghai, China). Hep G2 cell has been identified to be a HB-derived cell line (30), while BEL 7402 is a HCC cell line. Hep G2 cells were grown in Dulbecco's modified Eagle's medium (DMEM; Gibco; Thermo Fisher Scientific, Inc. Waltham, MA, USA) supplemented with $12 \%$ (v/v) fetal bovine serum (FBS; Gibco; Thermo Fisher Scientific, Inc.), $100 \mu \mathrm{g} / \mathrm{ml}$ streptomycin, and $100 \mathrm{U} / \mathrm{ml}$ penicillin. BEL 7402 cells were grown in RPMI-1640 medium (Gibco; Thermo Fisher Scientific, Inc.) supplemented with $10 \%$ (v/v) Fetal bovine serum (Gibco; Thermo Fisher Scientific, Inc.), $1.5 \mathrm{~g} / 1 \mathrm{NaHCO}_{3}$ (Sigma-Aldrich; Merck KGaA, Darmstadt, Germany), 2.5 g/l glucose (Sigma-Aldrich, USA), $0.11 \mathrm{~g} / 1$ sodium pyruvate (Sigma-Aldrich; Merck KGaA), $100 \mu \mathrm{g} / \mathrm{ml}$ streptomycin (Gibco; Thermo Fisher Scientific, Inc.), and $100 \mathrm{U} / \mathrm{ml}$ penicillin (Gibco; Thermo Fisher Scientific, Inc.). Cells were incubated at $37^{\circ} \mathrm{C}$ in a humidified atmosphere containing $5 \% \mathrm{CO}_{2}$ according to the standard procedure.

Chemicals. MA and ATO were obtained from Sigma-Aldrich (Merck KGaA). MA was diluted by anhydrous ethanol to a final concentration of $10 \mathrm{mM}$. ATO was firstly diluted in $1 \mathrm{mM} \mathrm{NaOH}$ (Sigma-Aldrich; Merck KGaA). Then, the alkaline solution with ATO was titrated by hydrochloric acid (Sinopharm Chemical Reagent Co., Ltd., Shanghai, China) to neutral. After that, the neutral solution was added with $\mathrm{ddH}_{2} \mathrm{O}$ to a final concentration of $10 \mathrm{mM}$ ATO. The stock solution of MA $(10 \mathrm{mM})$ and ATO $(10 \mathrm{mM})$ was filtered with $0.22 \mu \mathrm{m}$ syringe driven filters (EMD Millipore, Billerica, MA, USA), and then was stored in $-20^{\circ} \mathrm{C}$ no more than 1 month.

Cell proliferation assay. Hep G2 cells $\left(5 \times 10^{3}\right.$ cells/well) and BEL 7402 cells $\left(2 \times 10^{3}\right.$ cells/well) were independently seeded in 96-well cell culture plates and incubated overnight. Then, the culture medium was replaced with fresh one with or without drugs. After incubation for 24, 48, $72 \mathrm{~h}$, cell viability was evaluated using Cell Counting Kit-8 kit (Dojindo Molecular Technologies, Inc., Kumamoto, Japan) as described previously (31).

Analyses of apoptosis. Hep G2 and BEL 7402 cells were seed in 6 -well cell culture plates $\left(1 \times 10^{6}\right.$ cells/well) and incubated overnight. Then, culture media were removed and replaced with fresh media containing with or without drugs at $37^{\circ} \mathrm{C}$ for $24 \mathrm{~h}$. The cells were harvested, washed, and resuspended in phosphate-buffered saline (PBS). The apoptotic cell death rate was examined with Annexin V-FITC and PI double staining using the Annexin V-FITC apoptosis detection kit (Roche, Penzberg, Germany). After staining the cells with Annexin V-FITC/PI, flow cytometric analysis was performed by BD Accuri ${ }^{\mathrm{TM}}$ C6 personal flow cytometer (BD Biosciences, Franklin Lakes, NJ, USA), and the data was analyzed using FlowJo software (Tree Star, Ashland, OR, USA).

Western blotting. Proteins from Hep G2 and BEL 7402 cells treated with or without chemicals for $24 \mathrm{~h}$ were extracted with RIPA lysis (Beyotime Institute of Biotechnology, Haimen, China) buffer supplemented with protease inhibitor cocktail (Roche Diagnostics, Indianapolis, IN, USA) and phosphatase inhibitor (Roche Diagnostics) on ice. Then, the total proteins were fractionated using SDS-PAGE and then transferred to $0.45 \mu \mathrm{m}$ PVDF membrane (EMD Millipore). PVDF membranes containing proteins were blocked with 5\% skimmed milk at room temperature for $1 \mathrm{~h}$, and then stained with primary antibodies (Cell Signaling Technology, Inc., Danvers, MA, USA) overnight at $4^{\circ} \mathrm{C}$. Following washing, the membranes were incubated with appropriate secondary antibodies labeled by horseradish peroxidase (Cell Signaling Technology, Inc.) for $1 \mathrm{~h}$. Proteins were visualized by chemiluminescence procedures using Immobilon Western HRP Substrate (EMD Millipore). Blots were reproved with GADPH to compare protein load in each lane. All experiments were repeated three times.

Animal studies. Five-week-old BALB/C male nude mice weighing between 16 and $20 \mathrm{~g}$ were obtained from Shanghai SLAC laboratory Animal Co., Ltd. (SLAC; Shanghai, China). HepG2 cells were collected in $0.2 \mathrm{ml}$ of PBS, and the cell suspensions were then injected subcutaneously into mice $\left(5 \times 10^{6}\right.$ cells per mouse). When the tumors reached approximately $100 \mathrm{~mm}^{3}$, mice were randomized ( $\mathrm{n}=9 /$ group) to intraperitoneally administrated of drugs $(10 \mathrm{mg} / \mathrm{kg} / \mathrm{d} \mathrm{MA}$, $3.5 \mathrm{mg} / \mathrm{kg} / \mathrm{d}$ ATO or their combination) on daily for 20 consecutive days. Both of MA and ATO was diluted to $1 \mathrm{mg} / \mathrm{ml}$ in saline solution using ultrasonic waves. The volumes of the transplanted tumors were measured and estimated as previously described $(13,32)$. All procedures for care and use of animals were performed under national and international laws and policies. Experimental facilities and laboratory space was kindly provided by Hangzhou Hibio Bio-tech Co., Ltd. (Hangzhou, China). The ethical approval was obtained from Hangzhou Hibio Animal Care and Use Committee of the Hangzhou Hibio Bio-tech Co., Ltd. 
A

Hep G2

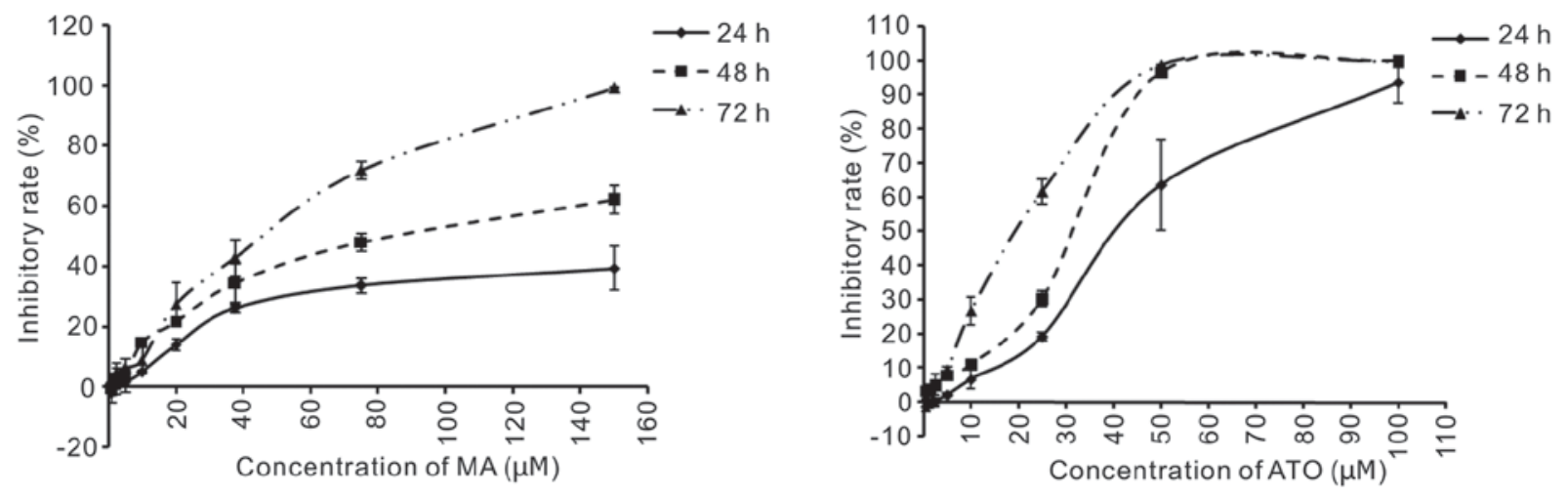

B

BEL 7402

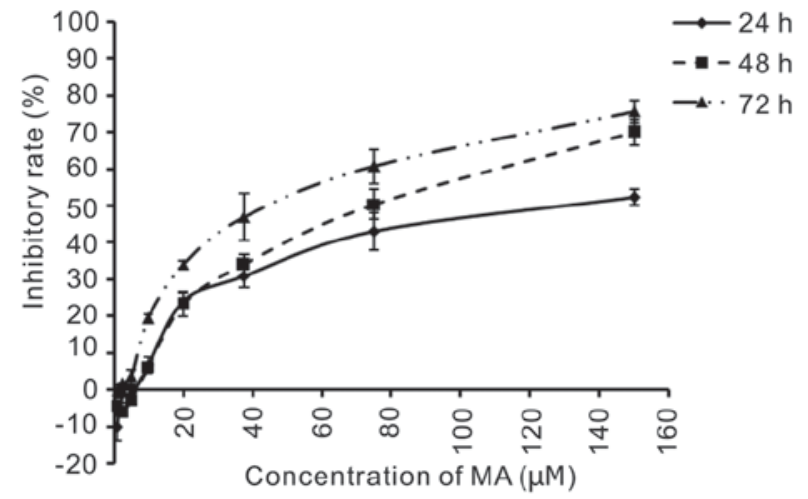

C
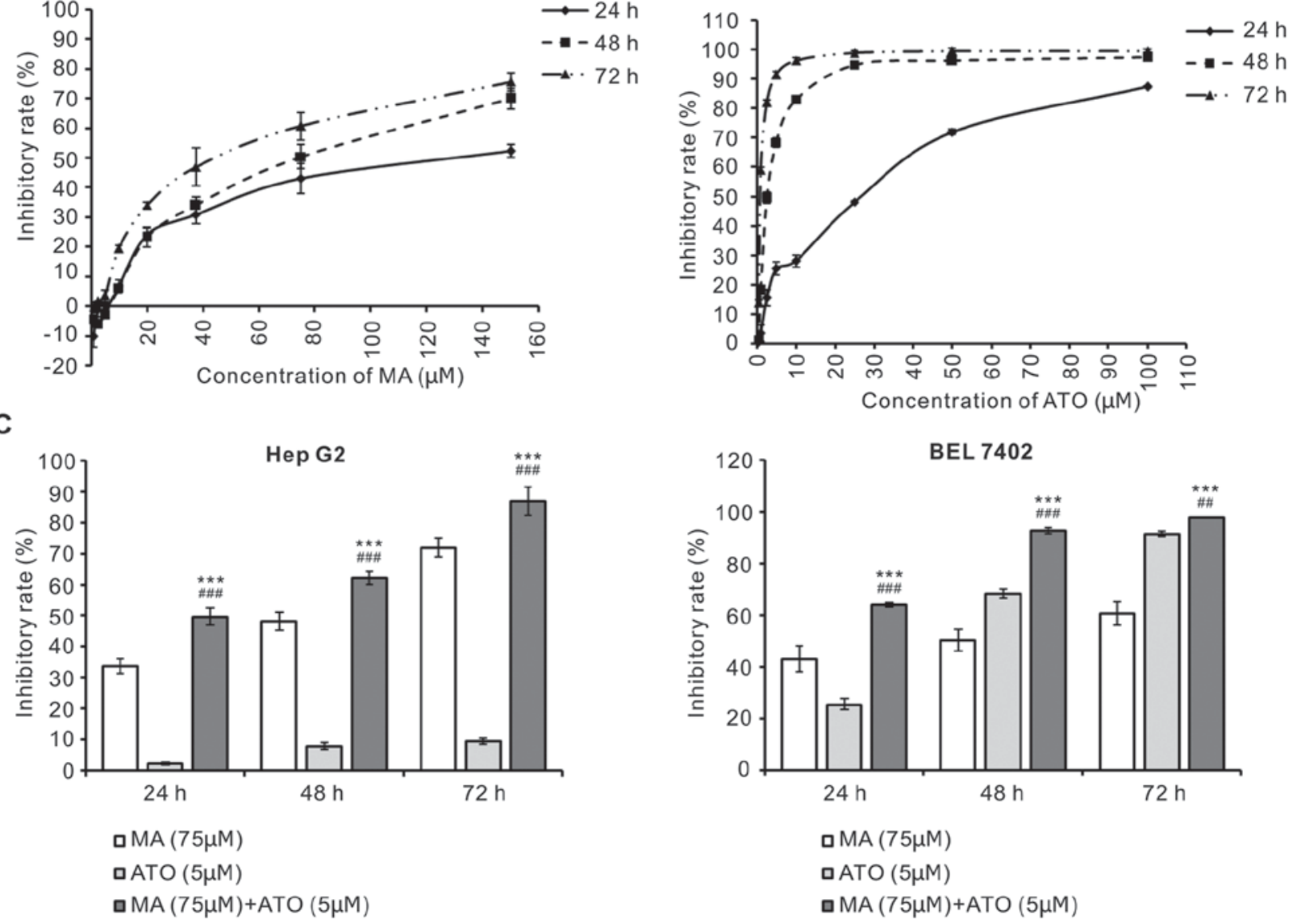

Figure 1. Growth inhibition by treatment with MA, ATO and a combination of MA/ATO on Hep G2 and BEL 7402 cells. (A) The Hep G2 cell inhibition rates following treatment with MA $(2.5,5,10,20,37.5,75$ and $150 \mu \mathrm{M})$ or ATO $(1,2.5,5,10,25,50$ and $100 \mu \mathrm{M})$ for 24, 48 and $72 \mathrm{~h}$. (B) The BEL 7402 cell inhibition rates following treatment with MA $(2.5,5,10,20,37.5,75$ and $150 \mu \mathrm{M})$ or ATO $(1,2.5,5,10,25,50$ and $100 \mu \mathrm{M})$ for 24,48 and $72 \mathrm{~h}$. (C) The growth inhibition rates following treatment with single-agent MA $(75 \mu \mathrm{M})$, single-agent ATO $(5 \mu \mathrm{M})$ or their combination in Hep G2 and BEL 7402 cells. Data were expressed as the mean \pm standard deviation $(\mathrm{n}=3) .{ }^{* * * *} \mathrm{P}<0.001$ vs. MA group; ${ }^{\# \#} \mathrm{P}<0.01$ and ${ }^{\# \# \#} \mathrm{P}<0.001$ vs. ATO group. MA, megestrol acetate; ATO, arsenic trioxide.

Statistical analysis. All data were analyzed using SPSS 16.0 (SPSS, Inc., Chicago, IL, USA) and Microsoft Excel (MicrosoftCorporation,Redmond,WA,USA).The experiments were repeated at least three times to ensure the reproducibility. Statistical data were expressed as means \pm standard deviation $(n \geq 3)$. A one-way analysis of variance (ANOVA) followed by a least significant difference test was adopted to analyze inter-group differences. $\mathrm{P}<0.05$ was considered to indicate a statistically significant difference.

\section{Results}

Combined MA/ATO treatment improved growth inhibition in Hep G2 and BEL 7402 cells. To evaluate the effect of MA and ATO on proliferation of HCC cells (Hep G2 and BEL 7402), cell viability was measured by CCK8 assay. The results indicated that single-agent MA or ATO inhibited cell growth by time and dose dependence (Fig. 1A and B). However, slightly increase of viability of BEL 7402 cells was observed in MA 
A

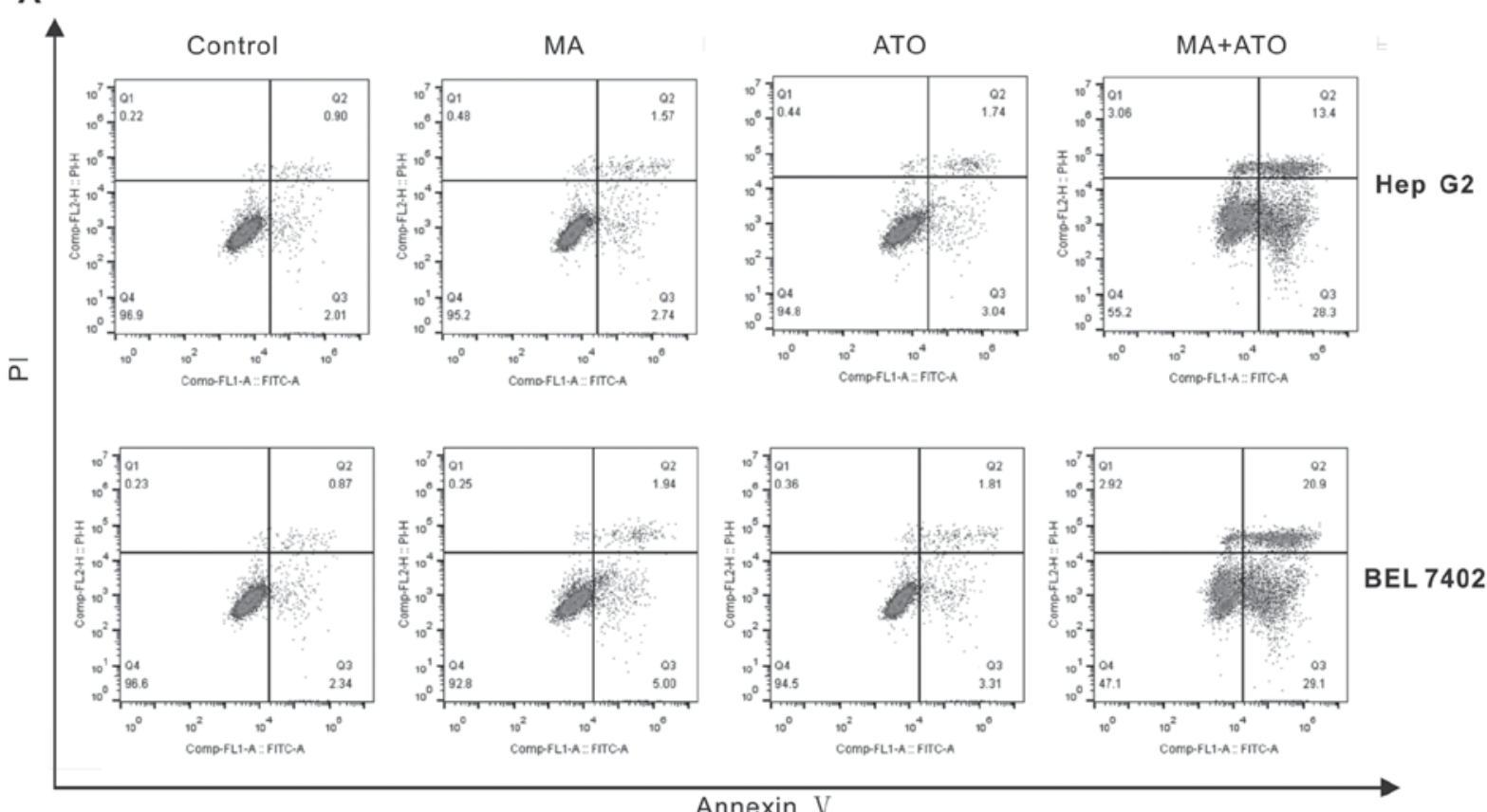

B
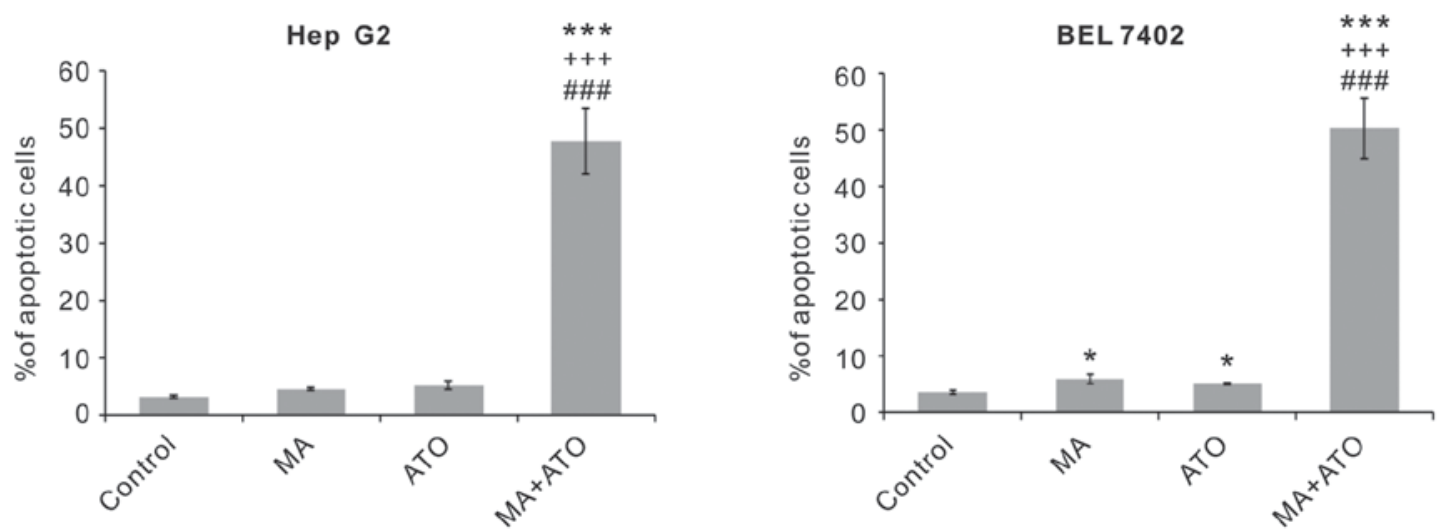

Figure 2. Co-treatment of MA/ATO enhanced apoptosis in liver cancer cell lines. Hep G2 and BEL 7402 cells were treated with anhydrous ethanol (Control), MA $(75 \mu \mathrm{M})$, ATO $(5 \mu \mathrm{M})$ and MA/ATO combination, for $24 \mathrm{~h}$. (A) Flow cytometry analysis of apoptosis with Annexin V and PI staining. (B) Statistical analysis of apoptotic data. A significant increase in the percentage of apoptotic cells was observed in the MA/ATO group. Data were expressed as the mean \pm standard deviation $(\mathrm{n}=3) .{ }^{*} \mathrm{P}<0.05$ and ${ }^{* * * *} \mathrm{P}<0.001$ vs. Control; ${ }^{++} \mathrm{P}<0.001$ vs. MA group; ${ }^{\# \# "} \mathrm{P}<0.001$ vs. ATO group. MA, megestrol acetate; ATO, arsenic trioxide; PI, propidium iodide.

group at low concentrations $(1,5 \mu \mathrm{M})$. The inhibition rates of single-agent MA $(75 \mu \mathrm{M})$ on Hep G2 cells were $33.58 \pm 2.36$, $48.09 \pm 2.97$, and $71.91 \pm 3.00 \%$ after treatment with 24,48 and $72 \mathrm{~h}$, respectively. The inhibition rates of single-agent MA $(75 \mu \mathrm{M})$ on BEL 7402 were 43.14 $\pm 5.06,50.37 \pm 4.11$ and $60.72 \pm 4.62 \%$ after treatment with 24,48 and $72 \mathrm{~h}$, respectively. Moreover, the inhibition rates of single-agent ATO $(5 \mu \mathrm{M})$ on Hep G2 were $2.15 \pm 0.45,7.88 \pm 1.21$ and $9.40 \pm 0.96 \%$ after treatment with 24, 48 and $72 \mathrm{~h}$, respectively. The inhibition rates of single-agent ATO $(5 \mu \mathrm{M})$ on BEL 7402 were 25.48 \pm 2.16 , $68.39 \pm 1.75$ and $91.46 \pm 0.96 \%$ after treatment with 24,48 and $72 \mathrm{~h}$, respectively. The combined treatment of MA $(75 \mu \mathrm{M})$ and ATO $(5 \mu \mathrm{M})$ significantly inhibited growth of Hep G2 and BEL 7402 cells compare to that in single-agent treatment (Fig. 1C). The inhibition rate of co-treatment of MA/ATO on Hep G2 cells was $49.72 \pm 2.80 \%$ (vs. MA, P<0.001; vs. ATO,

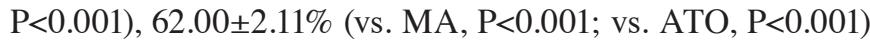
and $86.81 \pm 4.60 \%$ (vs. MA, $\mathrm{P}<0.001$; vs. ATO, $\mathrm{P}<0.001$ ) after 24, 48 and $72 \mathrm{~h}$, respectively, while it on BEL 7402 cells was $64.00 \pm 0.70 \%$ (vs. MA, $\mathrm{P}<0.001$; vs. ATO, $\mathrm{P}<0.001$ ), $92.82 \pm 1.17 \%$ (vs. MA, $\mathrm{P}<0.001$; vs. ATO, $\mathrm{P}<0.001$ ) and $97.80 \pm 0.24 \%$ (vs. MA, $\mathrm{P}<0.001$; vs. ATO, $\mathrm{P}<0.01$ ) after 24,48 and $72 \mathrm{~h}$, respectively.

Combined exposure to MA/ATO enhanced caspase 3 cleavage, PARP cleavage and apoptosis on Hep G2 and BEL 7402 cells. To examine apoptosis of Hep G2 and BEL 7402 cells treated with MA $(75 \mu \mathrm{M})$, ATO $(5 \mu \mathrm{M})$ and their combination for $24 \mathrm{~h}$, Annexin V/PI staining and flow cytometry was performed. As shown in Fig. 2, low level of apoptosis was detected in control group $(3.17 \pm 0.25 \%$ in Hep $\mathrm{G} 2$ cells, $3.52 \pm 0.30 \%$ in BEL 7402 cells), single-agent MA group 
A

Pro Caspase-3

Cleaved Caspase-3

GAPDH

MA

ATO
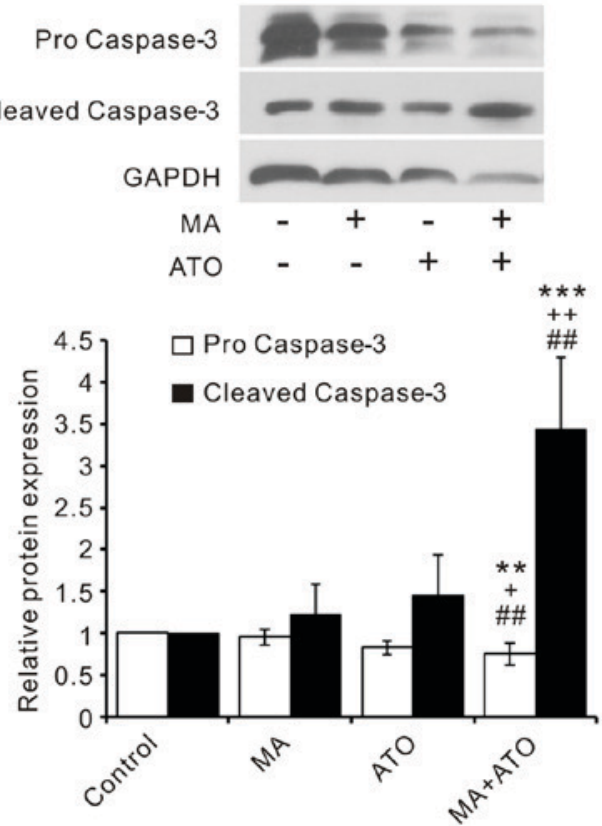

B
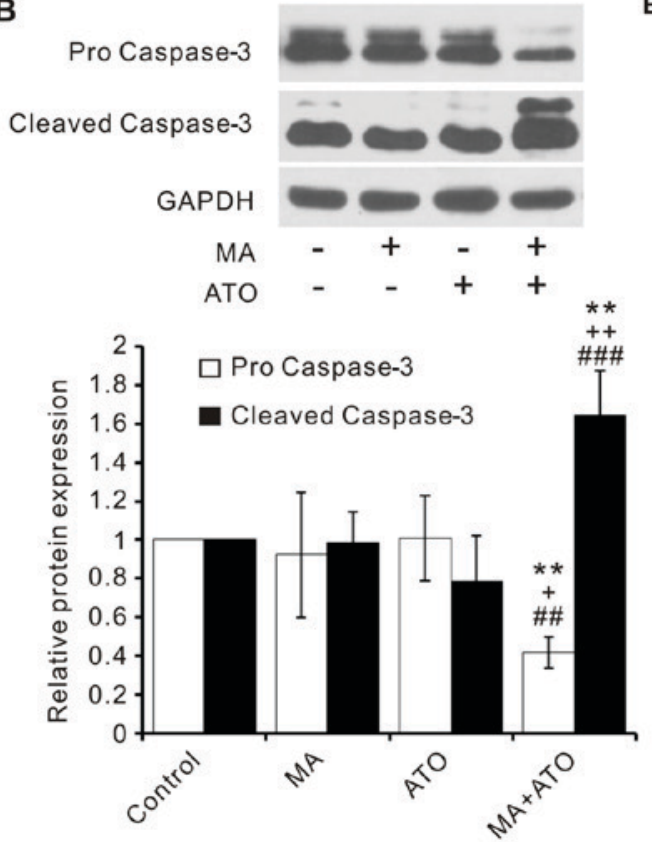

Hep G2
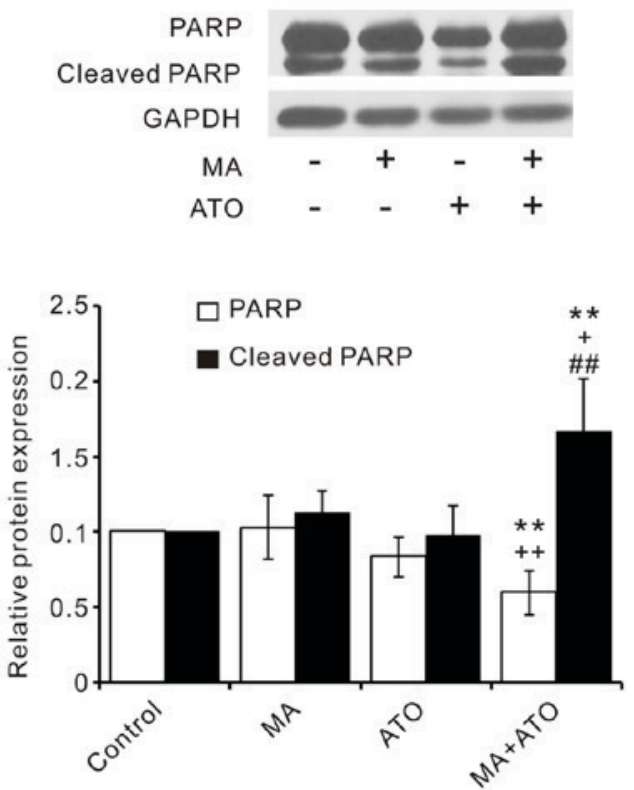

BEL 7402

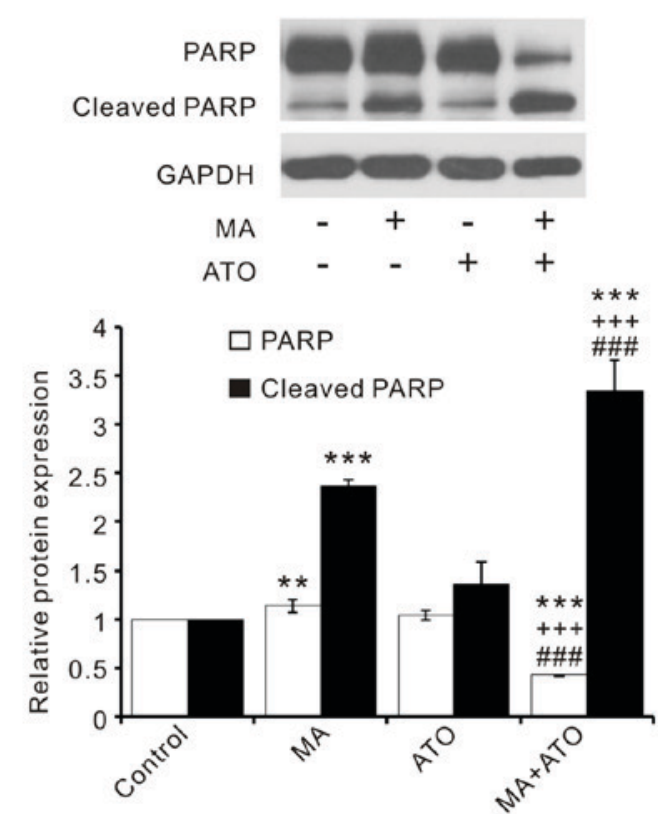

Figure 3. Combined treatment of MA/ATO markedly promoted the cleavage of caspase 3 and PARP. Hep G2 and BEL 7402 cells were treated with anhydrous ethanol (Control), MA (75 $\mu \mathrm{M})$, ATO $(5 \mu \mathrm{M})$ and MA/ATO combination, for $24 \mathrm{~h}$. Western blot analysis of cleavage form expression of caspase 3 and PARP in (A) Hep G2 cells and (B) BEL 7402 cells, respectively. Caspase 3 and PARP cleavage were significantly increased following treatment with MA/ATO in Hep G2 and BEL 7402 cell lines. Expression of GAPDH protein served as the loading control. Data were expressed as the mean \pm standard deviation (n=3). ${ }^{* *} \mathrm{P}<0.01$ and ${ }^{* * *} \mathrm{P}<0.001$ vs. Control; ${ }^{+} \mathrm{P}<0.05,{ }^{++} \mathrm{P}<0.01$ and ${ }^{++} \mathrm{P}<0.001$ vs. MA group; ${ }^{\# \#} \mathrm{P}<0.01$ and ${ }^{\# \#+} \mathrm{P}<0.001$ vs. ATO group. MA, megestrol acetate; ATO, arsenic trioxide; PARP, poly (adenosine 5'-diphsophate)-ribose polymerase; p-, phosphorylated.

(4.53 $\pm 0.24 \%$ in Hep G2 cells, $5.91 \pm 0.89 \%$ in BEL 7402 cells) and single-agent ATO group $(5.20 \pm 0.70 \%$ in Hep G2 cells, $5.15 \pm 0.16 \%$ in BEL 7402 cells). Interestingly, apoptotic levels was extremely enhanced in combination treatment of MA and ATO, up to $47.73 \pm 5.77 \%$ (vs. control, $\mathrm{P}<0.001$; vs. MA, $\mathrm{P}<0.001$; vs. ATO, $\mathrm{P}<0.001)$ in Hep G2 cells, and 50.27 $\pm 5.31 \%$ (vs. control, $\mathrm{P}<0.001$; vs. $\mathrm{MA}, \mathrm{P}<0.001$; vs. ATO, $\mathrm{P}<0.001)$ in BEL 7402 cells (Fig. 2A and B).

Activation of cysteine proteases (caspases) is the best recognized biochemical hallmark for apoptosis, while active caspase 3 is one of important markers reflecting the extent of apoptosis. In addition, cleavage of substrates of active caspase 3, such as poly (ADP)-ribose polymerase (PARP), was characteristic to most apoptotic cells (33). In order to further verify the effect of MA/ATO in apoptosis, caspase 3 and PARP cleavage immunoblots were conducted on Hep G2 and BEL 7402 cells after treatment of MA $(75 \mu \mathrm{M})$, ATO $(5 \mu \mathrm{M})$ and their combination for $24 \mathrm{~h}$. The relative protein expression of cleaved caspase 3 on Hep G2 cells was detected to be $1.23 \pm 0.35$ in MA group, $1.46 \pm 0.47$ in ATO group, and $3.43 \pm 0.85$ in MA/ATO combined group. Meanwhile, the relative protein expression of cleaved caspase 3 on BEL 
A
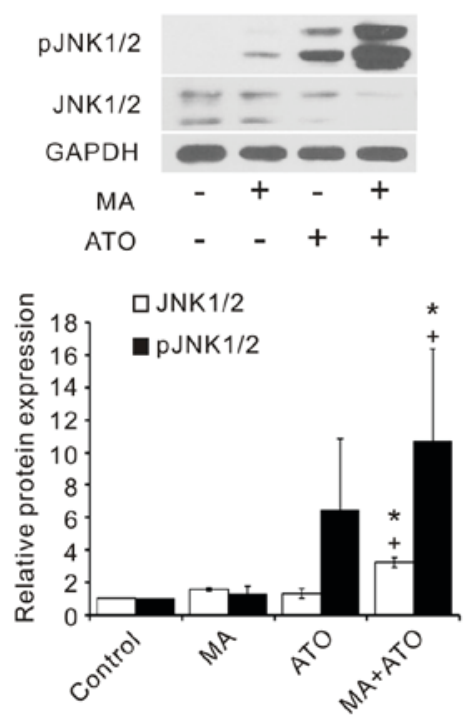

B

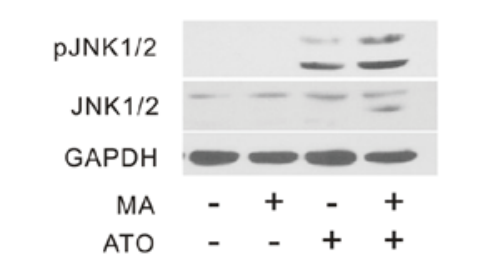

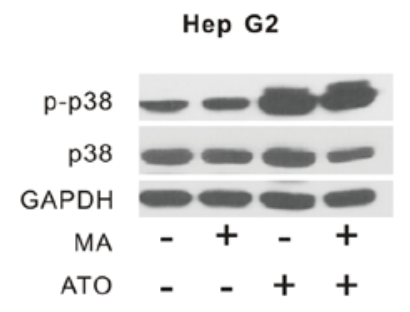
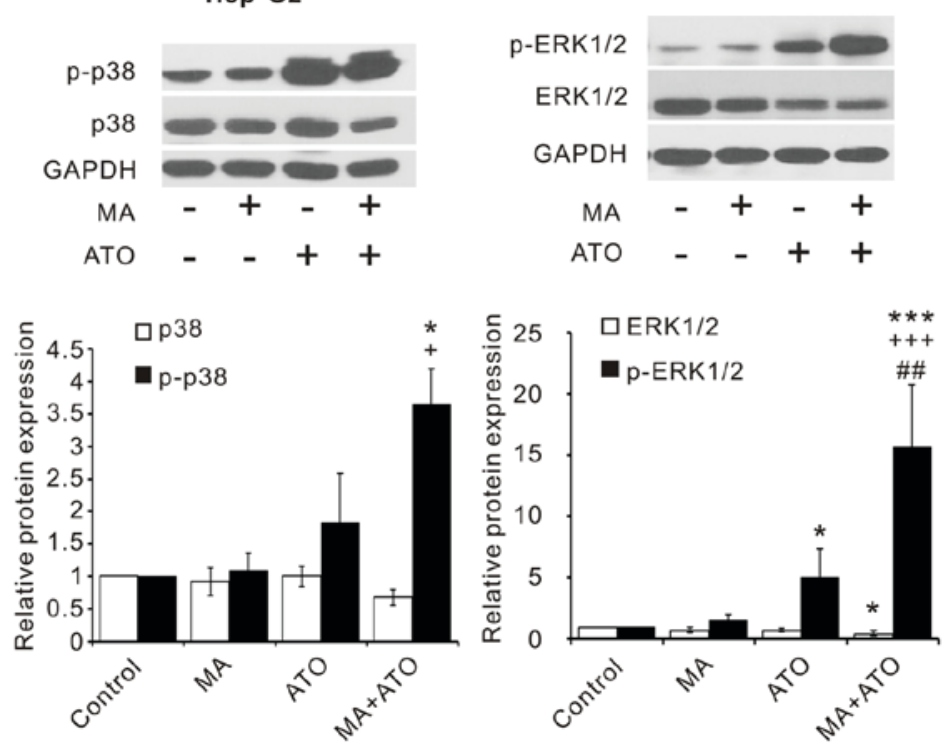

BEL 7402
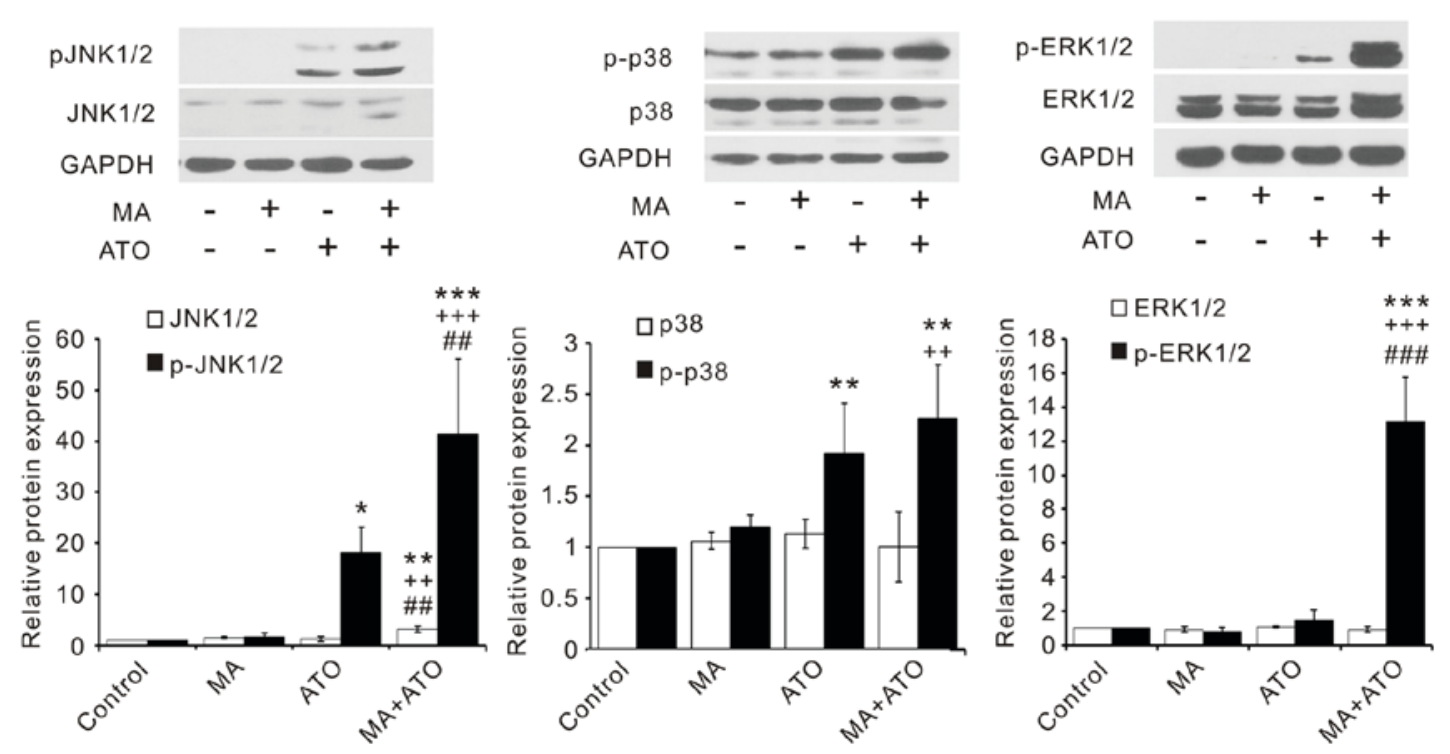

Figure 4. Combined treatment of MA/ATO increased the phosphorylation of p38, JNK1/2 and ERK1/2. Hep G2 and BEL 7402 cells were treated with anhydrous ethanol (Control), MA $(75 \mu \mathrm{M})$, ATO $(5 \mu \mathrm{M})$ and MA/ATO combination, for $24 \mathrm{~h}$. Western blot analysis of the phosphorylation of p38, JNK1/2 and ERK1/2 on (A) Hep G2 cells and (B) BEL 7402 cells, respectively. Activation of p38, JNK1/2 and ERK1/2 was highly enhanced by treatment with MA/ATO. Expression of GAPDH protein served as the loading control. Data were expressed as the means \pm standard deviation $(\mathrm{n}=3)$. ${ }^{*} \mathrm{P}<0.05,{ }^{* *} \mathrm{P}<0.01$ and ${ }^{* * *} \mathrm{P}<0.001$ vs. Control; ${ }^{+} \mathrm{P}<0.05,{ }^{++} \mathrm{P}<0.01$ and ${ }^{+++} \mathrm{P}<0.001$ vs. MA group; ${ }^{\# \#} \mathrm{P}<0.01$ and ${ }^{\# \# \#} \mathrm{P}<0.001$ vs. ATO group. MA, megestrol acetate; ATO, arsenic trioxide; JNK, c-Jun N-terminal kinase; ERK, extracellular signal-regulated kinase; p-, phosphorylated.

7402 cells was detected to be $0.99 \pm 0.15$ in MA group, $0.78 \pm 0.23$ in ATO group and $1.64 \pm 0.23$ in MA/ATO combined group. The relative protein expression of cleaved PARP on Hep G2 cells was detected to be $1.13 \pm 0.14$ in MA group, $0.94 \pm 0.20$ in ATO group and $1.66 \pm 0.35$ in MA/ATO combined group. The relative protein expression of cleaved PARP on BEL 7402 cells was detected to be $2.37 \pm 0.07$ in MA group, $1.35 \pm 0.23$ in ATO group and $3.35 \pm 0.31$ in MA/ATO combined group (Fig. 3A). The results revealed that both caspase 3 and PARP was significantly cleaved in co-treatment group of MA and ATO after $24 \mathrm{~h}$ in Hep G2. Besides, the expression levels of cleaved caspase 3 and cleaved PARP in BEL 7402 were found with the same trend (Fig. 3B).
Phosphorylation of p38, JNK1/2 and ERK1/2 was strongly induced by MA/ATO on Hep G2 and BEL 7402 cells. It was reported that ATO could induce apoptosis through activation of p38 and JNK $(18,34,35)$. To investigate whether co-treatment of MA/ATO affected MAPKs in HCC cells, phosphorylation levels of p38, JNK1/2 and ERK1/2 were measured by immunoblot. The results revealed that single agent MA could not induce significant changes of p-JNK1/2, p-p38 and p-ERK1/2 in both cell lines. In contrast, the expression of p-p38 (1.92 \pm 0.49 on BEL 7402 cells), p-JNK1/2 (18.24 44.95 on BEL 7402 cells) and p-ERK1/2 (5.04 \pm 2.27 on Hep G2 cells) was significantly enhanced by treatment of ATO compare to that in control (Fig. 4). Moreover, co-treatment of MA/ATO induced significantly increase of relative expression level of p-JNK1/2 
A

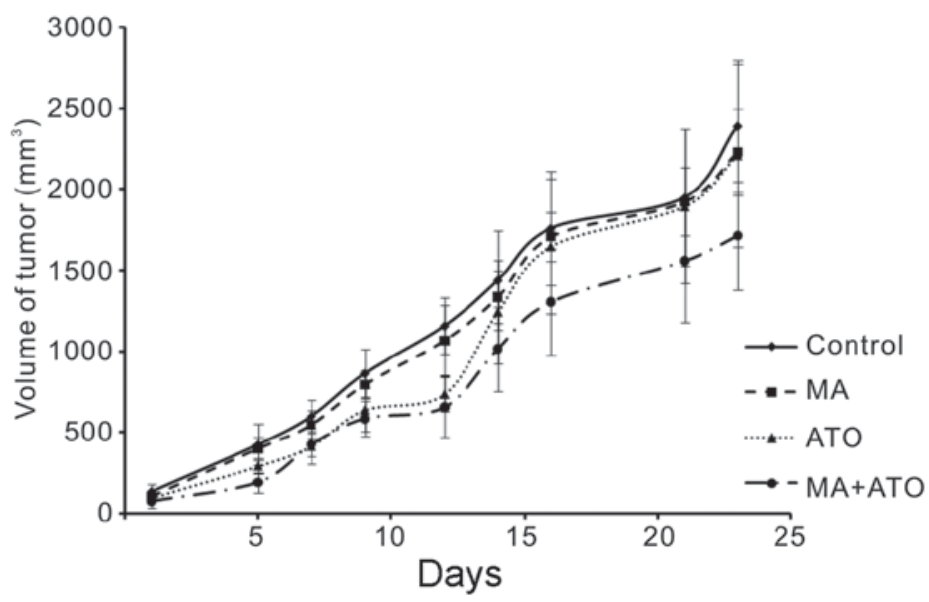

B

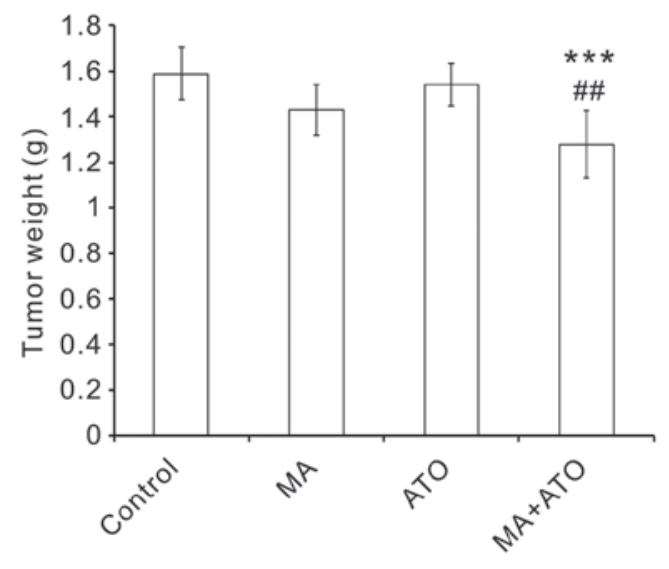

Figure 5. Co-treatment with MA/ATO significantly inhibited the growth of Hep G2 cells in a mouse model. Mice were administered with saline solution (Control), MA (10 mg/kg/day), ATO (3.5 mg/kg/day) or a combination of MA (10 mg/kg/day) and ATO (3.5 mg/kg/day). (A) Differences in tumor volume and

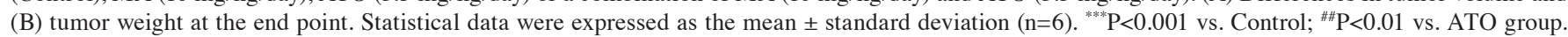
MA, megestrol acetate; ATO, arsenic trioxide.

(10.66 \pm 5.72$),$ p-p38 (3.64 \pm 0.55$)$ and p-ERK1/2 (15.69 \pm 4.99$)$ on Hep G2 cells compare to control group or single drug group, while the relative expression level of p-JNK1/2 (41.49 \pm 14.65$)$,

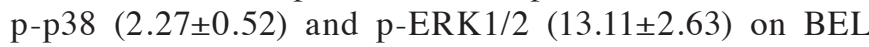
7402 cells was also obviously increased. It was suggested that activation of ERK1/2, p38 and JNK was highly induced by MA/ATO co-treatment.

Combined MA/ATO treatment suppress Hep G2 cell growth in vivo. To evaluate whether MA/ATO antitumor efficacy observed in vitro for HCC cells was recapitulated in vivo, nude mice harboring human liver cancer tumor (Hep G2 cells) were treated with the drugs. Consistence with the synergistic effect in vitro, combined MA/ATO treatment displayed enhanced antitumor activity without significant toxicity (Fig. 5). At the end point, it revealed a significant reduction of tumor weight in MA/ATO group (1.28 $\pm 0.15 \mathrm{~g})$ compared to that in control group $(1.59 \pm 0.12 \mathrm{~g})$ and in ATO group $(1.54 \pm 0.09 \mathrm{~g})$, respectively. Although there was no statistically significant regression of tumors in MA/ATO group than that in MA group $(1.43 \pm 0.11 \mathrm{~g})$, the average weight of tumor in MA/ATO group was lower than that in single-agent MA group. Besides, it was well tolerated without significant weight loss after 20 days of combined MA/ATO treatment (Data not shown). It indicated that MA/ATO treatment induces significant tumor regression in xenograft model with well toleration.

\section{Discussion}

MA has been used clinically for treatments of several malignancies, including ovarian cancer and breast cancer. MA (160 mg/day) was effective in inhibiting tumor growth or in improving anorexia, cachexia and performance status with minimal side effects in patients with advanced $\operatorname{HCC}(36,37)$. In contrast, it was revealed that there were some benefits with MA (320 mg/day) in improving appetite and reducing nausea/vomiting in HCC patients but without any function in prolonging OS (38). Thus, even though MA was proved to be with a low incidence of side effects in the dosage range up to $800 \mathrm{mg} /$ day (39), it was not recommend for treating liver cancer. It was reported that MA mediated growth inhibition of HB cell line Hep G2 in vitro and in vivo. In this study, we found that MA could inhibit cell growth in dosage and time dependent way on different liver cell lines, including HB cell line Hep G2 and HCC cell line BEL 7402. And inhibitory rates of MA were reached the peak at $75 \mu \mathrm{M}$ potentially cause of drug crystallization at the higher concentration. However, the results showed that MA either had no significant inhibition effect or contrarily promoted cell growth at low concentration on the cell lines. Thus, considering the conflicting outcomes of MA at different concentration, the inhibition efficacy of MA was potentially highly related to drug concentration.

Several studies revealed that ATO was effective for inhibiting proliferation of liver cancer cell lines, such as HB derived HepG2 cells, HCC derived SK-Hep-1 cells, and HCC derived $\mathrm{HuH7}$ cells (40-42). However, a phase II trial aimed at evaluating the efficacy and toxicity of ATO revealed that treatment of ATO alone in patients with HCC had no significant therapeutic benefit (25). Recently, studies about ATO focused on combination treatment with other drugs, such as icariin, metformin, shikonin, sorafenib. The results showed that combined treatments with ATO potentially enhanced the antitumor effect in HCC $(27-29,43,44)$. There was study showed that ATO induced mitochondrial apoptotic cell death by ROS increase which was potentially required for activations of p38 MAPK and JNK in human cervical cancer cells $(18,28,43)$. Notably, metformin synergized with ATO inhibited proliferation of intrahepatic cholangiocarcinoma cells potentially via promoting cell apoptosis and regulating AMPK/p38 MAPK-ERK3/mTORC1 pathways (45). In addition, combination treatment of indomethacin and ATO enhanced growth inhibition and apoptosis induction with remarkable phosphorylation of p38 and ERK1/2 in A549 lung cancer cells (46). In the present study, co-treatment of MA/ATO could strongly improve cell growth inhibition by apoptosis along with activation of caspase 3 and 
cleavage of PARP on liver cancer cells. Meanwhile, combined treatment of MA/ATO synergistically induced phosphorylation of JNK1/2, p38 as well as ERK1/2. Thus, the antitumor effect of MA/ATO combination potentially relied on apoptosis induction in which MAPK pathway was involved. However, the delicate mechanism of MA/ATO combination on inhibiting liver cancer cells need more extensive and in-depth studies.

In the present study, the tumor growth in nude mice harboring human liver cancer tumor (Hep G2 cells) was significantly inhibited by MA/ATO combination compare to that in control. It worth noting that Hep G2 cell line was proved to be originated from hepatoblastoma (30). Different from $\mathrm{HCC}$, hepatoblastoma is the most common primary malignant liver cancer in children (12). In the current study, the results of MA/ATO combination in evaluating the antitumor effect in vivo were very preliminary with a small sample size (6 of 9) just using a single HB cell line Hep G2. Thus, further investigations in vivo should be conducted using a larger number of mice bearing additional validated liver cell lines.

In conclusion, we investigated the antitumor effect and the potential underlying mechanism of co-treatment of MA/ATO on HCC cells. We demonstrated that combined treatment of MA/ATO significantly enhanced the cell growth inhibition effect, and leaded to increased induction of apoptosis and phosphorylation of $\mathrm{p} 38, \mathrm{JNK} 1 / 2$ and ERK1/2. Meanwhile, combined treatment of MA/ATO also induced tumor regression in vivo analyzed. These results suggested that combination of MA/ATO may be a potential strategy for the treatment of HCC.

\section{Acknowledgements}

We thank Dr. Wenlan Liu and Mingjun Wang for support of instruments.

\section{References}

1. Baffy G, Brunt EM and Caldwell SH: Hepatocellular carcinoma in non-alcoholic fatty liver disease: An emerging menace. J Hepatol 56: 1384-1391, 2012.

2. Costantini S, Di Bernardo G, Cammarota M, Castello G and Colonna G: Gene expression signature of human HepG2 cell line. Gene 518: 335-345, 2013.

3. Combs SE, Habermehl D, Ganten T, Schmidt J, Edler L, Burkholder I, Jäkel O, Haberer T and Debus J: Phase i study evaluating the treatment of patients with hepatocellular carcinoma (HCC) with carbon ion radiotherapy: The PROMETHEUS-01 trial. BMC Cancer 11: 67, 2011.

4. Colagrande $\mathrm{S}$, Inghilesi AL, Aburas S, Taliani GG, Nardi C and Marra F: Challenges of advanced hepatocellular carcinoma. World J Gastroenterol 22: 7645-7659, 2016.

5. Yeo W, Mok TS, Zee B, Leung TW, Lai PB, Lau WY, Koh J, Mo FK, Yu SC, Chan AT, et al: A randomized phase III study of doxorubicin versus cisplatin/interferon alpha-2b/doxorubicin/fluorouracil (PIAF) combination chemotherapy for unresectable hepatocellular carcinoma. J Natl Cancer Inst 97: 1532-1538, 2005.

6. Leung TW, Tang AM, Zee B, Yu SC, Lai PB, Lau WY and Johnson PJ: Factors predicting response and survival in 149 patients with unresectable hepatocellular carcinoma treated by combination cisplatin, interferon-alpha, doxorubicin and 5-fluorouracil chemotherapy. Cancer 94: 421-427, 2002

7. Di Maio M, Daniele B, Pignata S, Gallo C, De Maio E, Morabito A, Piccirillo MC and Perrone F: Is human hepatocellular carcinoma a hormone-responsive tumor? World J Gastroenterol 14: 1682-1689, 2008.
8. Toledo M,Penna F, Oliva F, Luque M, Betancourt A, Marmonti E, López-Soriano FJ, Argilés JM and Busquets S: A multifactorial anti-cachectic approach for cancer cachexia in a rat model undergoing chemotherapy. J Cachexia Sarcopenia Muscle 7: 48-59, 2016.

9. Loberg RD, Bradley DA, Tomlins SA, Chinnaiyan AM and Pienta KJ: The lethal phenotype of cancer: The molecular basis of death due to malignancy. CA Cancer J Clin 57: 225-241, 2007.

10. Sedlacek SM: An overview of megestrol acetate for the treatment of advanced breast cancer. Semin Oncol 15 (2 Suppl 1): S3-S13, 1988.

11. Bines J, Dienstmann R, Obadia RM, Branco LG, Quintella DC, Castro TM, Camacho PG, Soares FA and Costa ME: Activity of megestrol acetate in postmenopausal women with advanced breast cancer after nonsteroidal aromatase inhibitor failure: A phase II trial. Ann Oncol 25: 831-836, 2014.

12. Sharma D, Subbarao G and Saxena R: Hepatoblastoma. Semin Diagn Pathol 34: 192-200, 2017.

13. Zhang $\mathrm{K}$ and Chow PK: The effect of megestrol acetate on growth of HepG2 cells in vitro and in vivo. Clin Cancer Res 10: 5226-5232, 2004.

14. Villa E, Moles A, Ferretti I, Buttafoco P, Grottola A, Del Buono M, De Santis M and Manenti F: Natural history of inoperable hepatocellular carcinoma: Estrogen receptors' status in the tumor is the strongest prognostic factor for survival. Hepatology 32 : 233-238, 2000

15. Douer D and Tallman MS: Arsenic trioxide: New clinical experience with an old medication in hematologic malignancies. J Clin Oncol 23: 2396-2410, 2005

16. Kito M, Akao Y, Ohishi N, Yagi K and Nozawa Y: Arsenic trioxide-induced apoptosis and its enhancement by buthionine sulfoximine in hepatocellular carcinoma cell lines. Biochem Biophys Res Commun 291: 861-867, 2002.

17. Chiu HW, Tseng YC, Hsu YH, Lin YF, Foo NP, Guo HR and Wang YJ: Arsenic trioxide induces programmed cell death through stimulation of ER stress and inhibition of the ubiquitin-proteasome system in human sarcoma cells. Cancer Lett 356: 762-772, 2015.

18. Kang YH and Lee SJ: The role of p38 MAPK and JNK in Arsenic trioxide-induced mitochondrial cell death in human cervical cancer cells. J Cell Physiol 217: 23-33, 2008.

19. Yu D, Wang ZH and Zhu LY: Mechanism of arsenic trioxide-induced apoptosis in hepatic blastoma cells HepG2. Zhonghua Zhong Liu Za Zhi 25: 120-123, 2003.

20. Schaeffer HJ and Weber MJ: Mitogen-activated protein kinases: Specific messages from ubiquitous messengers. Mol Cell Biol 19: 2435-2444, 1999.

21. Kyriakis JM and Avruch J: Mammalian MAPK signal transduction pathways activated by stress and inflammation: A 10-year update. Physiol Rev 92: 689-737, 2012.

22. Yang SH, Sharrocks AD and Whitmarsh AJ: MAP kinase signalling cascades and transcriptional regulation. Gene 513: 1-13, 2013.

23. Sui X, Kong N, Ye L, Han W, Zhou J, Zhang Q, He C and Pan H: p38 and JNK MAPK pathways control the balance of apoptosis and autophagy in response to chemotherapeutic agents. Cancer Lett 344: 174-179, 2014.

24. Peluso I, Yarla NS, Ambra R, Pastore G and Perry G: MAPK signalling pathway in cancers: Olive products as cancer preventive and therapeutic agents. Semin Cancer Biol 2017 (Epub ahead of print).

25. Lin CC, Hsu C, Hsu CH, Hsu WL, Cheng AL and Yang $\mathrm{CH}$ : Arsenic trioxide in patients with hepatocellular carcinoma: A phase II trial. Invest New Drugs 25: 77-84, 2007.

26. Yu Z, Wu F, Chen L, Li Q, Wang C, Dong J and Xie SQ: ETME, a novel $\beta$-elemene derivative, synergizes with arsenic trioxide in inducing apoptosis and cell cycle arrest in hepatocarcinoma cells via a p53-dependent pathway. Acta Pharm Sin B 4: 424-429, 2014.

27. Zhai B, Jiang X, He C, Zhao D, Ma L, Xu L, Jiang H and Sun X: Arsenic trioxide potentiates the anti-cancer activities of sorafenib against hepatocellular carcinoma by inhibiting Akt activation. Tumour Biol 36: 2323-2334, 2015.

28. Li W, Wang M, Wang L, Ji S, Zhang J and Zhang C: Icariin synergizes with arsenic trioxide to suppress human hepatocellular carcinoma. Cell Biochem Biophys 68: 427-436, 2014.

29. Jiang H, Ma Y, Chen X, Pan S, Sun B, Krissansen GW and Sun X: Genistein synergizes with arsenic trioxide to suppress human hepatocellular carcinoma. Cancer Sci 101: 975-983, 2010 . 
30. Lopez-Terrada D, Cheung SW, Finegold MJ and Knowles BB Hep G2 is a hepatoblastoma-derived cell line. Hum Pathol 40: $1512-1515,2009$.

31. Chong Y, Zhang J, Guo X, Li G, Zhang S, Li C, Jiao Z and Shao M: MicroRNA-503 acts as a tumor suppressor in osteosarcoma by targeting L1CAM. PLoS One 9: e114585, 2014.

32. Kitagawa Y, Ueda M, Ando N, Ozawa S and Kitajima M: Effect of endogenous and exogenous EGF on the growth of EGF receptor-hyperproducing human squamous cell carcinoma implanted in nude mice. Br J Cancer 72: 865-868, 1995.

33. Choudhary GS, Al-Harbi S and Almasan A: Caspase-3 activation is a critical determinant of genotoxic stress-induced apoptosis. Methods Mol Biol 1219: 1-9, 2015.

34. Eguchi R, Fujimori Y, Takeda H, Tabata C, Ohta T, Kuribayashi K, Fukuoka $\mathrm{K}$ and Nakano T: Arsenic trioxide induces apoptosis through JNK and ERK in human mesothelioma cells. J Cell Physiol 226: 762-768, 2011

35. Mao J, Yang J, Zhang Y, Li T, Wang C, Xu L, Hu Q, Wang X, Jiang S, Nie X and Chen G: Arsenic trioxide mediates HAPI microglia inflammatory response and subsequent neuron apoptosis through p38/JNK MAPK/STAT3 pathway. Toxicol Appl Pharmacol 303: 79-89, 2016.

36. Villa E, Ferretti I, Grottola A, Buttafoco P, Buono MG, Giannini F, Manno M, Bertani H, Dugani A and Manenti F: Hormonal therapy with megestrol in inoperable hepatocellular carcinoma characterized by variant oestrogen receptors. Br J Cancer 84: 881-885, 2001.

37. Chao Y, Chan WK, Wang SS, Lai KH, Chi CW, Lin CY, Chan A, Whang-Peng J, Lui WY and Lee SD: Phase II study of megestrol acetate in the treatment of hepatocellular carcinoma. J Gastroenterol Hepatol 12: 277-281, 1997.

38. Chow PK, Machin D, Chen Y, Zhang X, Win KM, Hoang HH Nguyen BD, Jin MY, Lobo R, Findlay M, et al: Randomised double-blind trial of megestrol acetate vs placebo in treatment-naive advanced hepatocellular carcinoma. Br J Cancer 105 945-952, 2011
39. Farrar DJ: Megestrol acetate: Promises and pitfalls. AIDS Patient Care STDS 13: 149-152, 1999.

40. Siu KP, Chan JY and Fung KP: Effect of arsenic trioxide on human hepatocellular carcinoma HepG2 cells: Inhibition of proliferation and induction of apoptosis. Life Sci 71: 275-285, 2002.

41. Chan JY, Siu KP and Fung KP: Effect of arsenic trioxide on multidrug resistant hepatocellular carcinoma cells. Cancer Lett 236: 250-258, 2006.

42. Oketani M, Kohara K, Tuvdendorj D, Ishitsuka K, Komorizono Y, Ishibashi K and Arima T: Inhibition by arsenic trioxide of human hepatoma cell growth. Cancer Lett 183: 147-153, 2002.

43. Song J, Zhao Z, Fan X, Chen M, Cheng X, Zhang D, Wu F, Ying $X$ and Ji J: Shikonin potentiates the effect of arsenic trioxide against human hepatocellular carcinoma in vitro and in vivo. Oncotarget 7: 70504-70515, 2016.

44. Yang X, Sun D, Tian Y, Ling S and Wang L: Metformin sensitizes hepatocellular carcinoma to arsenic trioxide-induced apoptosis by downregulating Bcl 2 expression. Tumour Biol 36: 2957-2964, 2015.

45. Ling S, Xie H, Yang F, Shan Q, Dai H, Zhuo J, Wei X, Song P, Zhou L, Xu X and Zheng S: Metformin potentiates the effect of arsenic trioxide suppressing intrahepatic cholangiocarcinoma: Roles of p38 MAPK, ERK3 and mTORC1. J Hematol Oncol 10: $59,2017$.

46. Mandegary A, Torshabi M, Seyedabadi M, Amirheidari B, Sharif $\mathrm{E}$ and Ghahremani MH: Indomethacin-enhanced anticancer effect of arsenic trioxide in A549 cell line: Involvement of apoptosis and phospho-ERK and p38 MAPK pathways. Biomed Res Int 2013: 237543, 2013 